\title{
Employment characteristics and job loss in patients awaiting surgery on the hip or knee
}

\author{
K T Palmer, P Milne, J Poole, C Cooper, D Coggon
}

Occup Environ Med 2005;62:54-57. doi: 10.1136/oem.2004.014977

See end of article for authors' affiliations

author affiliations

Correspondence to: Dr K Palmer, MRC Environmental

Epidemiology Unit,

Southampton General

Hospital, Southampton

SO16 6YD, UK; ktp@mrc.

soton.ac.uk

Accepted

17 September 2004

\begin{abstract}
Aims: To investigate the factors, including size of organisation, associated with job loss in patients awaiting surgery to the hip or knee joint.

Methods: A questionnaire was mailed to 498 consecutive patients of working age listed at a district general hospital for major joint replacement, knee arthroscopy, or periacetabular osteotomy. Questions were asked about level of physical disability, duration of symptoms, employment circumstances at the time the joint problem began, and job changes since the onset of symptoms with their reasons. Analysis focused on those in work when their health problem began. Cox regression was used to examine risk factors for job loss related and unrelated to the joint problem, and results were summarised as adjusted hazard ratios (HRs) with $95 \%$ confidence intervals $(95 \% \mathrm{Cl})$.

Results: Responses came from $370(74 \%)$ of those mailed, including 278 who were in work when their joint problem began. Of these, $82(30 \%)$ had left their original job mainly or partly because of their joint disorder. Such job loss was more common in those employed in small businesses (HR for $<10 v \geqslant 10$ employees: $1.9,95 \% \mathrm{Cl} 1.2-3.0$ ) and those whose work involved standing for $>2$ hours per day (HR 2.7, $95 \% \mathrm{Cl}$ 1.2-6.1) No similar associations were found when jobs were left for other reasons. After adjustment for non-sedentary work the association with small business employment remained but was weaker (HR 1.5, 95\% Cl 0.9-2.5). Modifications to work and access to occupational health advice were not associated with better job retention.

Conclusions: In subjects with disabling hip or knee disease, job retention is poorer in those from small companies - a matter of concern given the rising prevalence of serious joint disease in the British workforce and the tendency of businesses to downsize and subcontract services to smaller enterprises.
\end{abstract}

$\mathrm{T}$ he burden of serious lower limb joint disease in working aged people is substantial. In England and Wales some 13000 replacements of hip or knee joints and 29000 endoscopies of the knee are carried out each year on adults aged 15-59 years. ${ }^{1}$ These represent nearly 1 in 5 of hip replacements and 1 in 8 of knee joint replacements across all age bands. Moreover, as the average age of the national workforce rises because of long term demographic trends, ${ }^{2}$ the prevalence of disabling joint disease among people in employment is beginning to grow. ${ }^{3}$ Physical and social functioning are often substantially restricted in patients awaiting major joint replacement compared with age matched controls from the general population. ${ }^{4}$

Surprisingly, given this background, only a few investigations have considered the impact of arthritis on labour participation and the factors associated with unemployment. $^{5-8}$ Interest has focused mostly on employment outcomes following surgery. ${ }^{9}$

No study to our knowledge has looked specifically at the occupational factors that bear on losing a job because of major lower limb joint disease. It might be supposed that disease severity, the physical demands of work, the scope for adjustments to the workplace, and access to occupational health advice could all influence this outcome, although direct empirical evidence is lacking. Moreover, the size of the employing organisation (large or small) and the circumstances of employment may be relevant. One plausible hypothesis is that small businesses find it more difficult to accommodate the disabled worker, resulting in a higher rate of job loss than in bigger companies.

In this study we aimed to describe the occupational factors that have influenced job loss in patients awaiting lower limb surgery.

\section{METHODS}

We mailed a questionnaire to 498 consecutive patients aged 16-64 years who were entered onto the orthopaedic waiting list at a district general hospital in Portsmouth, England during 2002 for knee or hip arthroplasty, knee arthroscopy, or periacetabular osteotomy of the hip. A complete listing by operation type was obtained for all 10 orthopaedic surgeons at the hospital, and every patient in the relevant age band was mailed a questionnaire and a reminder as necessary after an interval of three weeks. Ethical approval for the study was provided by the Isle of Wight, Portsmouth and South East Hants Local Research Ethics Committee.

The questionnaire asked about age and sex; current physical disability; duration of symptoms; employment circumstances at the time the joint problem began (in the "original job"); and job changes since the onset of symptoms with their reasons.

Current physical disability was scored against a checklist of questions on restricted activity derived from the physical functioning subscale of the Short-form 36 questionnaire. ${ }^{10}$ Aggregated scores were dichotomised into two groups of similar size, classed as "high" or "low".

Information was collected for the original job on: employment status (employed versus self-employed), working hours (full versus part-time), the employer's size $(<10$ employees versus $\geqslant 10$ ), and sector (public versus private), whether the work involved standing for $\geqslant 2$ hours/day (non-sedentary versus sedentary), whether there was access to occupational health advice, and whether there had actually been alterations to the job or workplace aimed at helping the affected worker (for example, altered hours or responsibilities, tool or workplace adaptations). 


\section{Key message}

- In subjects with disabling hip or knee joint disease, job retention is poorer if employed in very small companies.

Analysis was restricted to those in work when their hip or knee problem began. Three main outcomes were considered: (1) leaving the original job mainly or partly because of the hip or knee problem; (2) leaving the original job for an unrelated reason; and (3) being currently unemployed. Cox regression was used to examine risk factors for these prevalent employment outcomes (all of which were treated as occurring at a single time-point ${ }^{11}$ ), and results were summarised as hazard ratios (HRs) with 95\% confidence intervals (95\% CI) after adjustment for potential confounders. All analyses were performed with the aid of STATA 7.0 software.

\section{RESULTS}

Questionnaires were returned by 370 (74\%) subjects, the response rate being slightly higher at older ages and in women. Among the respondents were 278 who were in work when their joint problem began. Of these, 82 (30\%, 95\% CI $24-35 \%$ ) had left their original job mainly or partly because of the joint problem, $85(31 \%)$ for other reasons, and $74(27 \%$, $95 \%$ CI $22-32 \%$ ) were currently unemployed. Job loss because of the joint problem was substantial and similar for subjects listed to undergo each of the categories of operation.

The median interval since job loss in those quitting the original job because of their joint problem was 3.5 (interquartile range $0.8-6.5$ ) years. This compares with a median waiting time of 4-9 months for these categories of operation when the survey was conducted.

\section{Policy implications}

- The current business trend of downsizing and subcontracting to smaller enterprises may exacerbate job loss related to disabling lower limb joint disease, which is an increasingly common problem in the ageing workforce.

Altogether, 77 subjects (28\%, 95\% CI 23-33\%) reported that one or several modifications had been made to the original job to help them cope. The commonest alterations were: transfer of responsibilities to another worker (44 responses), altered working hours (25), procurement of new work equipment (17), transfer to different tasks (16), and transfer to a different workplace (13). New training, extra supervision, and physical adaptations to their workplace were rarely offered $(<2 \%)$. As expected, the likelihood of job modification was greater in those with access to an occupational health service (HR 2.8, 95\% CI 1.6-4.9); but it varied little by level of disability, work demands (sedentary versus not), and normal working hours (data not presented).

Overall, workers from very small companies $(<10$ employees) received job modification more often than those from larger enterprises (HR 1.5, 95\% CI 0.8-2.8), but within this were less often transferred to other tasks (3\% versus $7 \%$ ) or offered extra supervision or new training ( $0 \%$ versus $4 \%$ ).

Table 1 shows the risk of leaving the original job, because of the joint problem or for other reasons, according to personal characteristics and employment circumstances. HRs are presented with and without mutual adjustment. The univariate analysis indicated that, as expected, leaving the original job was more common among younger workers and when more time had elapsed since the onset of the symptoms. Also as expected, job loss because of the joint problem was more likely in those with greater current

Table 1 Associations with leaving the original job among patients who were in work when their hip or knee problem began

\begin{tabular}{|c|c|c|c|c|c|c|c|}
\hline & \multirow{3}{*}{$\begin{array}{l}\text { Still in } \\
\text { original job } \\
(n=105)\end{array}$} & \multicolumn{6}{|c|}{ Number* and $\mathrm{HR} \dagger(95 \% \mathrm{Cl})$} \\
\hline & & \multicolumn{3}{|c|}{$\begin{array}{l}\text { Left original job because of hip or knee } \\
\text { problem }(n=74)\end{array}$} & \multicolumn{3}{|c|}{ Left original job for another reason $(n=78)$} \\
\hline & & \multicolumn{2}{|c|}{ Unadjusted } & Adjusted $\ddagger$ & \multicolumn{2}{|c|}{ Unadjusted } & Adjusted $\ddagger$ \\
\hline \multicolumn{8}{|l|}{ Sex } \\
\hline Male & 49 & 37 & 1.0 & 1.0 & 33 & 1.0 & 1.0 \\
\hline Female & 56 & 37 & $0.9(0.6-1.5)$ & $0.9(0.5-1.5)$ & 45 & $1.1(0.7-1.7)$ & $1.3(0.7-2.3)$ \\
\hline \multicolumn{8}{|l|}{ Current age (years) } \\
\hline$\leqslant 34$ & 5 & 5 & $1.1(0.4-2.7)$ & $1.6(0.6-4.3)$ & 5 & $1.1(0.4-2.6)$ & $1.6(0.6-4.2)$ \\
\hline $35-44$ & 12 & 9 & $0.9(0.5-1.9)$ & $1.2(0.6-2.5)$ & 6 & $0.7(0.3-1.6)$ & $0.9(0.4-2.1)$ \\
\hline $45-54$ & 29 & 10 & $0.6(0.3-1.1)$ & $0.7(0.3-1.3)$ & 14 & $0.7(0.4-1.2)$ & $0.7(0.4-1.3)$ \\
\hline $55-65$ & 59 & 50 & 1.0 & 1.0 & 53 & 1.0 & 1.0 \\
\hline Duration of symptoms§ & 105 & 74 & $1.5(1.1-1.9)$ & $1.4(1.1-1.9)$ & 78 & $1.6(1.3-1.9)$ & $1.6(1.3-2.0)$ \\
\hline \multicolumn{8}{|l|}{ Current disability } \\
\hline Low & 67 & 30 & 1.0 & 1.0 & 42 & 1.0 & 1.0 \\
\hline High & 38 & 44 & $1.7(1.1-2.8)$ & $1.6(1.0-2.6)$ & 36 & $1.3(0.8-2.0)$ & $1.1(0.7-1.7)$ \\
\hline \multicolumn{8}{|l|}{ Type of work } \\
\hline Sedentary & 28 & 6 & 1.0 & 1.0 & 27 & 1.0 & 1.0 \\
\hline Non-sedentary & 77 & 68 & $2.7(1.2-6.1)$ & $2.0(0.8-5.0)$ & 51 & $0.8(0.5-1.3)$ & $0.9(0.5-1.5)$ \\
\hline \multicolumn{8}{|l|}{ Working hours } \\
\hline Full-time & 76 & 49 & 1.0 & 1.0 & 61 & 1.0 & 1.0 \\
\hline Part-time & 29 & 25 & $1.2(0.7-1.9)$ & $1.2(0.7-2.2)$ & 17 & $0.8(0.5-1.4)$ & $0.8(0.5-1.6)$ \\
\hline \multicolumn{8}{|l|}{ Size of organisation } \\
\hline$\geqslant 10$ & 89 & 46 & 1.0 & 1.0 & 62 & 1.0 & 1.0 \\
\hline$<10$ & 16 & 28 & $1.9(1.2-3.0)$ & $1.5(0.9-2.5)$ & 16 & $1.2(0.7-2.1)$ & $1.0(0.5-1.8)$ \\
\hline
\end{tabular}

*Numbers restricted to those providing full information.

†All hazard ratios calculated relative to remaining in the original job.

†Adjusted for all of the factors in the table.

§uration of symptoms was analysed as a continuous variable and hazard ratios are for a ten year increase in duration. 
disability (HR 1.7) and those in non-sedentary work (HR 2.7, 95\% CI 1.2-6.1). Such job loss was also significantly more common among those in small firms (HR 1.9, 95\% CI 1.2-3.0 for $<10 \quad v \geqslant 10$ employees). But there was no similarly increased risk of leaving the original job for reasons unrelated to hip or knee disease. After mutual adjustment, the pattern was similar but risk estimates were a little lower and the HR for small business employment was 1.5 (95\% CI 0.9-2.5).

A comparable analysis was carried out with current unemployment as the outcome variable (data not tabulated). After adjusting for high current disability (HR 1.9), risks were again higher among those who had originally worked for a small employer (HR 1.7, 95\% CI 1.1-2.7).

After allowance for the risk factors in table 1, employment outcome differed little by employment status or sector of employment; and was not much changed in those with access to an occupational health service or whose original job was modified to accommodate their disabilities (table 2).

\section{DISCUSSION}

Much of the modern effort in orthopaedics is directed at achieving a functional improvement in cases coming to surgery, such that they may return to their former job. ${ }^{9}$ Our data suggest, however, that many of the recipients of these efforts will already have suffered job loss.

This is perhaps as expected, although reports on this important topic are few in number. Several population based surveys have found higher unemployment in arthritis sufferers. In the US National Health Survey, employment was $20-25 \%$ lower in working aged adults with self-reported arthritis than in those without; ${ }^{5}$ in the 1990 Ontario Health Survey, an even bigger differential was reported, especially for those in whom symptoms limited everyday activities; ${ }^{7}$ and in the cross-sectional Canadian National Population Health Survey of 58000 subjects, working life expectancy among those with self-reported arthritis or rheumatism (excluding back pain) was reduced across all five-year age bands between 15 and 64 years of age. ${ }^{8}$ These reports did not specify the site of disease, but data were disaggregated and presented separately for the lower limb in the Mini-Finland Survey. ${ }^{6}$ In a population sample of Finns aged $\geqslant 30$ years, some $15 \%$ of those with clinically verified hip osteoarthritis were completely unable to work, as were $23 \%$ of those with knee osteoarthritis.

Such surveys confirm that arthritis is a frequent cause of work limitation. But this report is novel in attempting to describe how antecedent work circumstances could impact on employment outcomes. Risk of job loss ascribed to serious hip or knee disease was related both to the physical demands of work (standing) and the size of employing organisation. Modified duties were more often provided for those with access to occupational healthcare, but little evidence of benefit was found in terms of job retention-either from the adjustments themselves or from access to occupational health advice.

In interpreting this study a number of limitations need to be considered. Firstly, the response rate $(74 \%)$ was incomplete. This may have led to a biased estimate of the prevalence of job loss and its associations if responders differed from non-responders in these characteristics. However, the proportions who had given up their job because of their hip or knee disorder were similar in those who responded to the questionnaire at the first invitation and those who responded only after a reminder $30 \%$ versus $28 \%)$; and there were broadly similar associations in the two groups between this outcome and the principal risk factors considered (data not presented). This provides some evidence against important response bias.

A second issue concerns self-reporting of work circumstances and the potential for biased or inaccurate recall. Nonsedentary work, for example, may have been remembered best by those who fared badly and surrendered a job. If present, such a bias would lead to an exaggerated association between the activity and the adverse employment outcome. (As a check on this possibility we examined the occupations in which standing was reported, and those in which it was not, and found the responses to be plausible.) It seems unlikely, however, that such errors could contribute to the observed association with small size of organisation as a risk factor.

A third consideration is the relatively small sample sizes when different reasons for quitting employment were considered separately. This has resulted for some adjusted analyses in lower confidence intervals that straddle unity. Replication of the findings on a larger scale and in other international settings would be a useful further step.

Finally, conclusions regarding the ineffectiveness of workplace interventions and occupational health services should be regarded as tentative. Possibly, adaptations were offered preferentially to those with the greatest need, or conversely to likely job survivors; and no evidence exists as to whether job adaptations were well chosen or effectively implemented. Prospective investigation with more detailed assessment is needed to resolve these uncertainties.

We place greater confidence in the finding that workers from small firms are at higher risk of job loss. This is a new and potentially far reaching discovery. "Micro-firms", defined by the UK Department of Trade and Industry as

Table 2 Associations of leaving the original job with employment status, access to an occupational health service, and workplace adaptations

\begin{tabular}{|c|c|c|c|c|c|c|c|}
\hline \multirow{3}{*}{ Employment status } & \multicolumn{7}{|c|}{ Number and $\mathrm{HR}^{*}(95 \% \mathrm{Cl})$} \\
\hline & \multirow{3}{*}{$\begin{array}{l}\begin{array}{l}\text { Still in original } \\
\text { job }\end{array} \\
97\end{array}$} & \multicolumn{2}{|c|}{$\begin{array}{l}\text { Left original job because } \\
\text { of hip or knee problem }\end{array}$} & \multicolumn{2}{|c|}{$\begin{array}{l}\text { Left original job for } \\
\text { another reason }\end{array}$} & \multicolumn{2}{|c|}{ Currently unemployed } \\
\hline & & & & & & & \\
\hline & & 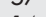 & & 14 & & & \\
\hline Self-employed & 8 & 14 & $1.0(0.5-2.2)$ & 4 & $0.7(0.2-2.1)$ & 15 & $0.9(0.4-1.8)$ \\
\hline Public sector & 44 & 23 & 1.0 & 22 & 1.0 & 21 & 1.0 \\
\hline Private sector & 59 & 46 & $1.1(0.6-1.8)$ & 56 & $1.3(0.8-2.2)$ & 63 & $1.3(0.8-2.2)$ \\
\hline \multicolumn{8}{|c|}{ Access to $\mathrm{OH}$ service } \\
\hline No & 59 & 49 & 1.0 & 52 & 1.0 & 63 & 1.0 \\
\hline Yes & 28 & 16 & $1.2(0.6-2.2)$ & 16 & $0.9(0.5-1.7)$ & 16 & $1.0(0.5-1.7)$ \\
\hline Unsure & 15 & 8 & $0.9(0.4-2.0)$ & 8 & $0.8(0.4-1.6)$ & 8 & $0.8(0.4-1.7)$ \\
\hline \multicolumn{8}{|c|}{ Workplace adaptation(s) } \\
\hline Yes & 35 & 20 & 1.0 & 13 & 1.0 & 20 & 1.0 \\
\hline No & 70 & 54 & $0.9(0.5-1.5)$ & 65 & $0.7(0.4-1.3)$ & 68 & $0.9(0.5-1.5)$ \\
\hline
\end{tabular}

*All hazard ratios were calculated relative to remaining in the original job, and adjusted for the factors in table 1. 
having fewer than 10 workers, comprise $95 \%$ of all businesses in the UK and employ around $30 \%$ of the total workforce. ${ }^{12}$ Our data suggest that people with arthritis who are employed by micro-firms are no less likely to receive job modifications, but are more likely to leave their job because of their hip or knee problem and more likely to be currently unemployed. This higher risk does not appear to be explained by a confounding effect of self-employment (almost all selfemployed subjects worked in micro-firms) or having access to an occupational health service (which was largely confined to larger enterprises). The absence of a similar association with job loss for other reasons argues against generally higher occupational mobility among people who work in micro-firms, and their increased risk of current unemployment suggests that the adverse impact of the higher rate of enforced job loss was in some cases long term.

The poorer job retention of disabled workers in micro-firms may arise in part from the different physical demands of work in small companies. Our estimate of relative risk adjusted for sedentary work was lower (HR 1.5) and fell just short of statistical significance. Another possibility is that more limited flexibility exists to accommodate disability in a small workforce. Workers from small companies were less often transferred to other work or offered extra supervision or retraining. Whatever the reason, these observations are of concern given the growing tendency of businesses to downsize and subcontract their work to smaller enterprises. Thus, the number of workers in small firms in the UK increased by one third between 1980 and 2001. ${ }^{12}$ As the average age of the national workforce rises and disabling joint disease becomes more common, the wisdom of this policy may be thrown into question.

\section{ACKNOWLEDGEMENTS}

We wish to thank the orthopaedic surgeons of Queen Alexandra Hospital, Portsmouth for their kind support and the MRC staff who assisted with mailing and data entry. Previa UK Limited covered the costs of the mailing.

\section{Authors' affiliations}

K T Palmer, J Poole, C Cooper, D Coggon, MRC Environmental Epidemiology Unit, Community Clinical Sciences Division, University of Southampton, Southampton General Hospital, Southampton SO16 6YD, UK

P Milne, Previa UK Ltd, QinetiQ, Farnborough GU14 OLX, UK

\section{REFERENCES}

1 Department of Health. Free Data: Hospital Episode Statistics 2001-2. http:// www.doh.gov.uk/hes/free_data/index.html (accessed 9 February 2004).

2 Cruijsen $\mathbf{H}$, de Beer J, de Jong A, et al. Latest population projections for the European Union, Population Trends no. 90. London: Office of National Statistics, 1997.

3 Holte HH, Tambs K, Bjerkedal T. Time trends in disability pensioning for rheumatoid arthritis, osteoarthritis and soft tissue rheumatism in Norway, 1968-97. Scand J Public Health 2003;31:17-23.

4 Croft P, Lewis M, Wynn-Jones $C$, et al. Health status in patients awaiting hip replacement for osteoarthritis. Rheumatism 2002;41:1001-7.

5 Yelin EH, Katz PP. Labor force participation among persons with musculoskeletal conditions, 1970-1987: national estimates derived from a series of cross-sections. Arthritis Rheum 1991;34:1361-70.

6 Heliovaara M, Makela M, Sievers K. Tuki-ja liikuntaelinten sairaudet Suomessa [Musculoskeletal disorders in Finland], Publication of the Social Insurance Institution. AL: 35, Helsinki:Social Insurance Institution, 1993.

7 Badley EM, Wang PP. The contribution of arthritis and arthritis disability to nonparticipation in the labor force: a Canadian example. J Rheumatol 2001;28: 1077-82.

8 Lacille D, Hogg RS. The effect of arthritis on working life expectancy. J Rheumatol 2001;28:2315-19.

9 Espehaug B, Havelin LI, Engesaeter LB, et al. Patient satisfaction and function after primary and revision total hip replacement. Clin Orthop 1998;351:135-48.

10 Ware JE. SF-36 Health Status Questionnaire. Boston, MA: Institute for the Improvement of Medical Care and Health, New England Medical Center Hospital, Quality Quest Inc., 1989.

11 Lee J, Chia KS. Estimation of prevalence rate ratios for cross-sectional data: an example in occupational epidemiology. Br J Ind Med 1993;50:861-2.

12 Small Business Services. http://www.sbs.gov.uk/statistics/ laccessed 9 February 2004) 